\title{
Pengaruh Jenis Pelarut terhadap Kandungan Senyawa Metabolit Sekunder Klika Kayu Jawa (Lannea coromendelica)
}

\section{Effect of the type of solvent on Contents of Secondary Metabolite Compounds of Kayu Jawa Klika (Lannea coromendelica)}

\author{
Hartati $^{1)^{*}}$, Syamsuddin B ${ }^{1)}$, Hilda Karim ${ }^{1)}$ \\ ${ }^{1}$ Prodi Biologi, FMIPA, Universitas Negeri Makassar \\ Received 27 $7^{\text {th }}$ July 2019/ Accepted 20 ${ }^{\text {th }}$ August 2019
}

\begin{abstract}
ABSTRAK
Kayu Jawa (Lannea coromendelica) merupakan tumbuhan yang tersebar di berbagai daerah dan memiliki potensi untuk dieksplorasi dalam pemanfaatannya. Penelitian ini bertujuan untuk mengeksplorasi Kayu Jawa (Lannea coromendelica) dengan menentukan jenis pelarut dan cara ekstraksi terbaik dalam mengekstraksi kandungan senyawa metabolit sekunder klika Kayu Jawa (Lannea coromendelica). Ekstraksi di lakukan dengan metode maserasi menggunakan pelarut etil asetat dan etanol 70\% serta menggunakan sampel kering dan basah, sehingga di peroleh 4 macam ekstrak yaitu Ekstrak etanol 70\% klika Kayu Jawa basah (KJBE70\%), ekstrak etanol 70\% klika Kayu Jawa kering (KJKE70\%), ekstrak etil asetat klika Kayu Jawa kering (KJKEA), dan ekstrak klika Kayu Jawa basah (KJBEA). Senyawa metabolit sekunder yang terdapat pada Kayu Jawa (Lannea coromendelica) adalah flavonoid, saponin, tanin, dan triterpenoid. Ekstrak klika Kayu Jawa basah (KJBEA) memiliki kandungan senyawa metabolit sekunder tertinggi sebanyak 3 senyawa yaitu flavonoid, saponin, dan tanin.
\end{abstract}

Kata Kunci : Jenis Pelarut, Metabolit Sekunder, Kayu Jawa

\begin{abstract}
Java wood (Lannea coromendelica) is a plant that is spread in various regions and has the potential to be explored in its use. This study aims to explore Java Wood (Lanneacoromendelica) by determining the type of solvent and the best method of extraction in extracting the content of secondary metabolites of Java Wood clica (Lanneacoromendelica). Extraction was carried out by maceration method using ethyl acetate and ethanol 70\% solvent and using dry and wet samples, so that four kinds of extracts were obtained, namely $70 \%$ ethanol extract of wet Java wood clica (KJBE70\%), 70\% ethanol extract of dry Java wood clica (KJKE70\%), dry Java woodclicaethyl acetate extract (KJKEA), and wet Java wood clica extract (KJBEA) The secondary metabolite compounds found in Javanese wood (Lannea coromendelica) are flavonoids, saponins, tannins, and terpenoids. Wet Java wood clica extract (KJBEA)
\end{abstract}

*Korespondensi:

email: hartati@unm.co.id 
has the highest secondary metabolite compound content of three compounds namely flavonoids, saponins, and tannins.

Key word: Solvent type, Secondary metabolites, Lannea coromendelica

\section{PENDAHULUAN}

Kayu Jawa (Lannea coromendelica) adalah tumbuhan dari keluarga Anacardiaceae, merupakan pohon tropis dan tumbuh secara liar sehingga mudah didapat diberbagai tempat seperti halaman rumah, tepi jalan, dan kebun milik penduduk. Kayu jawa banyak terdistribusi di pulau Sulawesi khususnya di daerah SulawesiSelatan.Kayu Jawa tidak hanya dijadikan sebagai tanaman pagar dan makanan ternak akan tetapi secara empiris telah digunakan oleh masyarakat Sulawesi-selatan terutama suku Bugis dan Makassar sebagai obat tradisional dikarenakan Kayu Jawa memiliki khasiat yang dipercaya sangat ampuh untuk mengobati luka dalam maupun luka luar seperti sariawan, sakit gigi, diare, memar, dan luka bakar. Penggunaan lain Kayu Jawa adalah sebagai analgesik, anti ulkus, dan aphrodisiac, getahnya sebagai penyembuhan luka, daunnya mengobati pembengkakan akibat keseleo, serta memiliki potensi dijadikan antioksidan, antimikroba, dan antiinflamasi (Tiwariet al., 2011).

Kemampuan Kayu Jawa untuk mengobati berbagai luka didasarkan atas peranan senyawa kimia yang mempunyai aktifitas biologis (zat bioaktif) yang terkandung didalamnya. Senyawa bioaktif tersebut merupakan senyawa yang berasal dari adaptasi biokimia yang dilakukan oleh tumbuhan pada umumnya termasuk Kayu Jawa. Senyawa-senyawa kimia ini menurut Subhashini et al., (2013) disintesis oleh jalur metabolik sekunder yang tidak terlibat dalam pertumbuhan normal, perkembangan atau reproduksi tetapi biasanya memiliki peran dalam proses adaptasi dalam kondisi stress.

Beberapa penelitian telah mendokumentasikan kelimpahan metabolit sekunder yang dimiliki oleh Kayu Jawa diantaranya oleh Manik et al., (2013) yang menyebutkan bahwa Kayu Jawamengandung senyawa golongan karbohidrat, steroid, glikosida, terpenoid, tanin, dan flavonoid.

Anggitha (2012) menyatakan bahwa efektivitas ekstraksi senyawa metabolit dalam suatu tanaman oleh pelarut sangat tergantung kepada kelarutan senyawa tersebut dalam pelarut, sesuai dengan prinsip suatu senyawa akan terlarut pada pelarut dengan sifat kepolaran yang sama. Penggunaan jenis pelarut berkaitan dengan polaritas dari pelarut tersebut sehingga memberikan pengaruh terhadap senyawa fitokimia yang dihasilkan.

Berdasarkan uraian tersebut mengenai kelimpahan metabolit sekunder yang terkandung pada klika Kayu Jawa serta diketahuinya bahwa pelarut yang digunakan menentukan senyawa yang di hasilkan maka, diperlukan suatu penelitian yang bertujuan untuk mengetahui pengaruh jenis pelarut terhadap hasil metabolit sekunder klika Kayu Jawa. 


\section{METODE PENELITIAN}

Alat

Perangkat alat gelas, spatula, parut, blender, neraca analitik, rak tabung, oven, dan mikropipet.

\section{Bahan}

Sampel uji (klika Kayu Jawa) etil asetat, etanol 70\%, reagen mayer, metanol, serbuk magnesium $(\mathrm{Mg})$, asam klorida pekat $(\mathrm{HCl})$, kloroform $\left(\mathrm{CHCl}_{3}\right)$, asam asetat anhidrida $\left(\mathrm{C}_{4} \mathrm{H}_{6} \mathrm{O}_{3}\right)$, asam sulfat pekat $\left(\mathrm{H}_{2} \mathrm{SO}_{4}\right)$, besi klorida $\left(\mathrm{FeCl}_{3}\right) 3 \%$, akuades $\left(\mathrm{H}_{2} \mathrm{O}\right)$, natrium hidroksida $1 \mathrm{~N}(\mathrm{NaOH})$, kertas whatman, dan aluminium foil.

\section{Prosedur Kerja}

Meliputi pengkajian literatur, persiapan sampel, pembuatan ekstrak, dan skrining fitokimia.

\section{Preparasi Sampel}

Klika Kayu Jawa disortasi basah dan dibilas untuk menghilangkan kotoran kemudian dikering anginkan. Klika Kayu Jawa yang diparut dinamakan simplisia basah sedangkan klika Kayu Jawa simplisia kering disiapkan dengan di keringkan pada oven suhu $40^{\circ} \mathrm{C}$ kemudian dihaluskan menggunakan blender. Pembuatan Ekstrak.Klika Kayu Jawa basah dan kering diekstraksi dengan metode maserasi menggunakan pelarut etil asetat dan etanol 70\%.Sampel kayu jawa basah dan kering ditimbang 350 gram dan direndam dengan masing-masing pelarut sampai simplisia terendam. Pelarut diganti setiap 1 x 24 jam dan diulangi sebanyak 3 kali. Sampel yang direndam disaring menggunakan kertas whatman dan dipekatkan dengan Rotary vacum evaporator suhu $40^{\circ} \mathrm{C}$ sehingga diperoleh ekstrak kental Etanol 70\% klika Kayu Jawa basah (KJBE70\%), ekstrak kental Etil Asetat klika kayu jawa basah (KJBEA), ekstrak kental Etanol 70\% klika Kayu Jawa kering (KJKE70\%), ekstrak kental Etil asetat klika Kayu Jawa Kering (KJKEA). Persentase rendemen dihitung dengan rumus:

$$
\% \text { Rendemen }=\frac{\text { bobot total ekstrak }}{\text { berat bubuk simplisia total }} \times 100 \%
$$

\section{Skrining Fitokimia.}

Analisis senyawa dilakukan untuk mengetahui metabolit sekunder yangterkandung pada ekstrak klika Kayu Jawa. Analisis tersebut melipitu beberapa pengujian yaitu:

a. Uji Alkaloid

Uji menggunakan reagen Wagner yaitu 0,1 gram sampel dilarutkan dalam $10 \mathrm{ml}$ metanol. Mengambil $2 \mathrm{ml}$ filtrat ditambahkan $1 \mathrm{ml}$ reagen wagner. Uji menggunakan reagen Meyer yaitu 0,1 gram sampel dilarutkan dalam $10 \mathrm{ml}$ metanol. Mengambil $2 \mathrm{ml}$ filtrat ditambahkan $1 \mathrm{ml}$ reagen meyer.Terbentuk warna putih dengan reagen Mayer dan endapancoklat kemerahan dengan reagen Wagner menunjukkan adanyasenyawa golongan alkaloid.

b. Uji Flavonoid

Uji Reagen $\mathrm{Mg}$ dan $\mathrm{HCl}$ dengan 0,1 gram dilarutkan dalam $10 \mathrm{ml}$ metanol. Sampel diambil $2 \mathrm{ml}$ kemudian ditambahkan 0,05 mg serbuk Mg dan $1 \mathrm{ml} \mathrm{HCL}$ 
pekat, kemudian kocok. Uji positif ditunjukkan dengan terbentuknya warna merah, kuning atau jingga. Uji timbal asetat yaitu 0,1 gram sampel dilarutkan dalam $10 \mathrm{ml}$ metanol. Sampel diambil $2 \mathrm{ml}$ kemudian ditambahkan $1 \mathrm{ml} \mathrm{Pb}$ asetat $10 \%$ dan dikocok. Uji positif ditunjukkan dengan perubahan warna menjadi coklat kekuningan.

c. Uji Tanin

Sampel 0,1 gram dilarutkan pada $10 \mathrm{ml}$ metanol. Sampel diambil $2 \mathrm{ml}$ kemudian ditambahkan 3 tetes $\mathrm{FeCl}_{3}$ 3\%. Adanya endapan hijau kehitaman menandakan adanya tanin.

d. Uji Saponin

Sampel 0,5 gram kemudian ditambahkan $5 \mathrm{ml}$ air suling pada tabung reaksi. Larutan dikocok secara perlahan dan diamati hingga terbentuk busa yang stabil.

e. Uji Triterpenoid dan Steroid

Sampel 0,1 gram dilarutkan pada kloroform ditambahkan asam asetat anhidrida $0,5 \mathrm{ml}$ kemudian ditambahkan $2 \mathrm{ml}$ asam sulfat pekat melalui dinding tabung. Terbentuknya warna merah atau coklat menandakan positif triterpenoid dan warna hijau sedangkan warna biru menandakan positif steroid.

\section{HASIL PENELITIAN}

Hasil Ekstrak Klika Kayu Jawatertinggi yaitu pada ekstrak etanol 70\% klika Kayu Jawa kering (KJKE70\%) sebesar 20,09 gram, ekstrak etanol 70\% klika Kayu Jawa basah (KJBE70\%) sebesar 18,22 gram, ekstrak etil asetat klika Kayu Jawa basah (KJBEA) sebesar 10,05 gram dan ekstrak etil asetat klika Kayu Jawa kering (KJKEA) sebesar 6,18 gram. Nilai rendeman dari masing-masing ekstrak secara berturut-turut yaitu sebesar 5,73\%, 5,21\%, 2,87\%, dan 1,76\%. Perbandingan hasil rendeman berbagai ekstrakdapat dilihat pada Gambar 1.

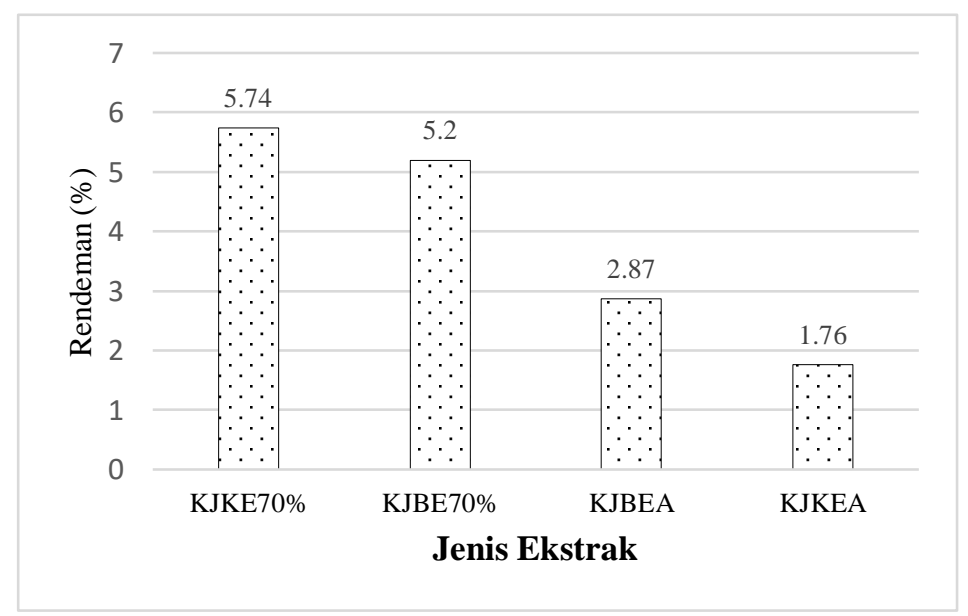

Gambar 1. Hasil Persentase Rendemen KJKE70\% (Ekstrak etanol 70\% klika Kayu Jawa kering), KJBE70\% (Ekstrak etanol 70\% klika Kayu Jawa basah), KJBEA (Ekstrak etil asetat klika Kayu Jawa basah), dan KJKEA ( Ekstrak etil asetat klika Kayu Jawa kering) 
Golongan senyawa yang terdapat pada ekstrak klika Kayu Jawaditentukan dengan tes uji warna menggunakan pereaksi. Hasil perubahan warna ekstrak dapat dilihat pada Gambar 2.

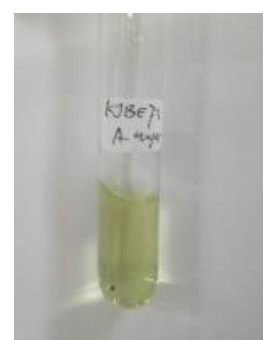

(a)

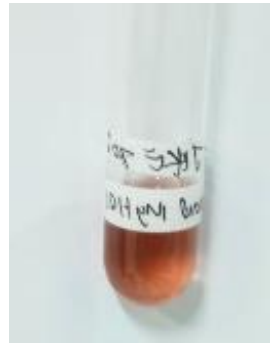

(f)

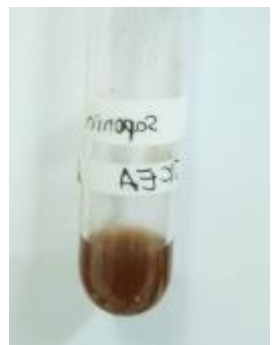

$(\mathrm{k})$

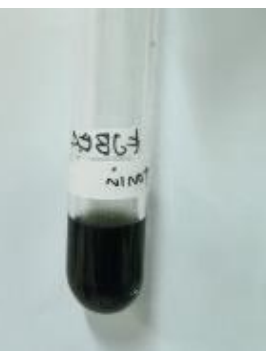

(p)

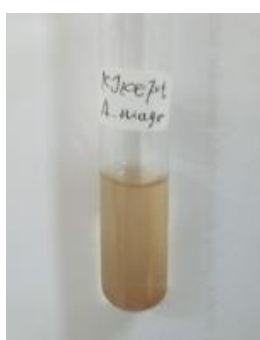

(b)

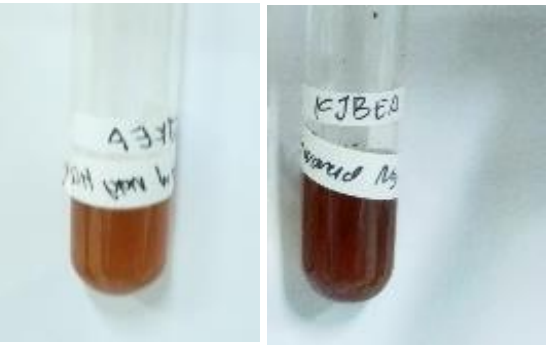

$(\mathrm{g})$

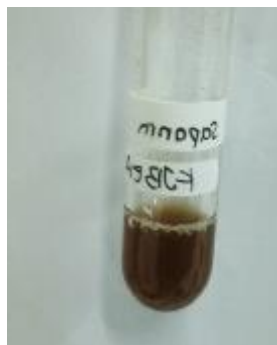

(1)

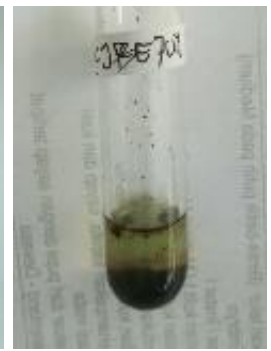

(q)

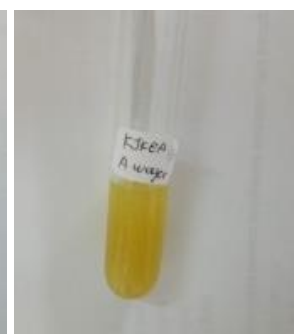

(c)

(h)

(m)

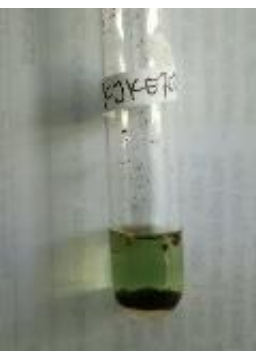

(r)

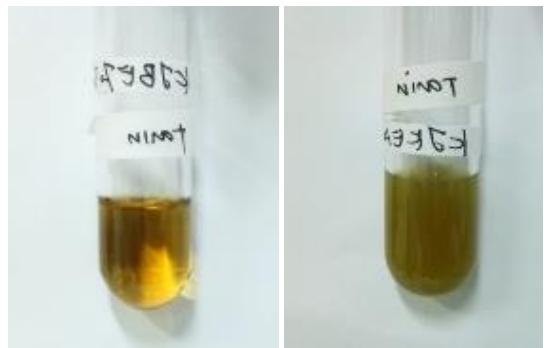

(n)

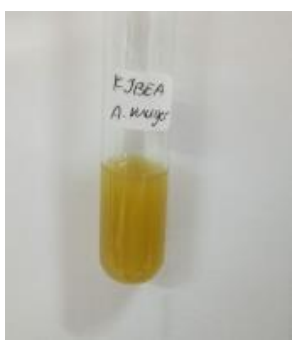

(d)

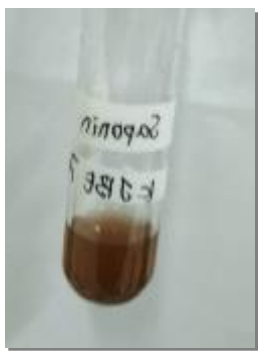

(i)

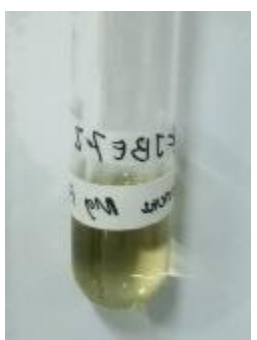

(e)

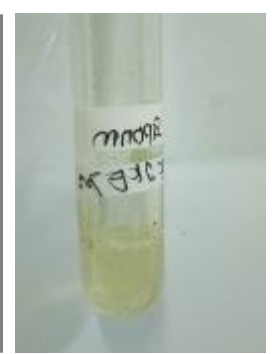

(j)

Gambar 2. Hasil skrining fitokimia: Uji alkaloid ekstrak (a) KJBE70\%, (b) KJKE70\%, (c) KJKEA, (d) KJBEA; Uji flavonoid ekstrak (e) KJBE70\%, (f) KJKE70\%, (g) KJKEA, (h) KJBEA; Uji saponin ekstrak (i) KJBE70\%, (j) KJKE70\%, (k) KJKEA, (l) KJBEA; Uji tanin ekstrak (m) KJBE70\%, (n) KJKE70\%, (o) KJKEA, (p) KJBEA; Uji steroid dan triterpenoid ekstrak (q) KJBE70\%, (r) KJKE70\%, (s) KJKEA, dan (t) KJBEA. 
Berdasarkan perubahan warna yang terjadi pada ekstrak klika Kayu Jawa dihasilkan bahwa setiap ekstrak memiliki kandungan senyawa metabolit sekunder berbeda-beda sebagaimana ditampilkan pada tabel 1 .

Tabel 1. Hasil Skrining Fitokimia

\begin{tabular}{|c|c|c|c|c|c|}
\hline \multirow{2}{*}{$\begin{array}{l}\text { Identifikasi } \\
\text { Senyawa }\end{array}$} & \multirow[b]{2}{*}{ Pereaksi } & \multicolumn{4}{|c|}{ Sampel } \\
\hline & & $\begin{array}{c}\text { KJBE70 } \\
\%\end{array}$ & KJKE70\% & KJKEA & KJBEA \\
\hline Alkaloid & Mayer & - & - & - & - \\
\hline Flavonoid & Serbuk $\mathrm{Mg}+\mathrm{HCl}$ & - & + & + & + \\
\hline Saponin & Aquades & - & + & - & + \\
\hline Tanin & $\mathrm{FeCl} 3 \%$ & + & + & - & + \\
\hline Steroid & \multirow{2}{*}{$\begin{array}{c}\text { Asam asetat } \\
\text { anhidrat+Asam sulfat }\end{array}$} & - & - & - & - \\
\hline Triterpenoid & & - & - & + & - \\
\hline
\end{tabular}

Keterangan:

$(+)=$ Mengandung senyawa yang dimaksud

$(-)=$ Tidak mengandung senyawa yang dimaksud

KJBE70\% = Ekstrak etanol 70\% klika Kayu Jawa basah

KJKE70\% = Ekstrak etanol 70\% klikaKayu Jawa kering

KJKEA $=$ Ekstrak etil asetat klika Kayu Jawa kering

$\mathrm{KJBEA}=$ Ekstrak etil asetat klika Kayu Jawa basah

Berdasarkan Tabel 1 diatas menunjukkan bahwa ekstrak KJBE70\% mengandung senyawa tanin, ekstrak KJKE70\% dan KJBEA mengandung senyawa flavonoid, saponin, dan tanin sedangkan ekstrak KJKEA mengandung senyawa flavonoid dan triterpenoid.

\section{PEMBAHASAN}

\section{Ekstraksi sampel klika Kayu Jawa}

Hasil penelitian menunjukkan bahwa rendemenekstrak etanol 70\% klika Kayu Jawa kering (KJKE70\%) dan ekstrak etanol klika Kayu Jawa basah (KJBE70\%) lebih besar dibandingkan dengan ekstrak etil asetat klika Kayu Jawa basah (KJBEA) dan ekstrak klika Kayu Jawa kering (KJKEA) hal ini menunjukkan bahwa jenis pelarut dan cara ekstraksi mempengaruhi jumlah ekstrak yang dihasilkan.

Ekstrak pelarut etil asetat lebih kecil dibandingkan dengan pelarut etanol $70 \%$ dikarenakan adanya gugus metoksi yang terdapat pada struktur kimia etil asetat yang menyebabkan terbentuknya ikatan hidrogen dengan senyawa yang terdapat pada sampel. Ikatan hidrogen yang terbentuk pada pelarut etil asetat lebih lemah dibandingkan dengan ikatan hidrogen yang terbentuk pada pelarut etanol 70\% sehingga mempengaruhi hasil rendemen dari pelarut etil asetat yang lebih kecil (Romadanu, 2014). Disamping itu, etanol $70 \%$ memiliki kandungan akuades sekitar $30 \%$ sehingga mempengaruhi bobot ekstrak yang dihasilkan. 
Ekstrak KJKE70\% dan KJBE70\% didapatkan dengan ekstraksi cara kering dimana tingkat kehalusan dan penghancuran bahan lebih tinggi dibandingkan dengan cara basah. Harborne (1987) menyatakan bahwa struktur molekul yang makin sederhana menyebabkan porositas atau pori-pori bahan makin besar, sehingga pelarut makin mudah berdifusi ke dalam sel-sel bahan yang diekstraksi.Besar kecilnya nilai rendemen menunjukkan keefektifan proses ekstraksi. Keefektifanproses ekstraksi dapat dipengaruhi oleh jenis pelarut yang digunakan, ukuran partikel sampel, lamanya waktu ekstraksi, dan metode ekstraksi yang digunakan (Alviana et al., 2016).

Berdasarkan data skrining fitokimia (Tabel 1), setiap ekstrak klika Kayu Jawa yang diperoleh dengan pelarut dan cara ekstraksi berbeda dihasilkan kandungan senyawa metabolit sekunder yang berbeda pula. Perbedaan ini didasarkan atas kemampuan pelarut yang berbeda dalam melarutkan kandungan kimia pada bahan yang digunakan. Perbedaan hasil skrining fitokimia dapat disebabkan pula oleh perbedaan kepekaan cara ekstraksi yang digunakan terhadap jumlah kandungan kimia dari bahan alam yang diuji.

\section{Analisis skrining fitokimia}

Berdasarkan data skrining fitokimia (Tabel 1), setiap ekstrak klika Kayu Jawa yang diperoleh dengan pelarut dan cara ekstraksi berbeda dihasilkan kandungan senyawa metabolit sekunder yang berbeda pula. Efektivitasekstraksi pada suatu senyawa oleh pelarut sangattergantung kepada kelarutan senyawatersebut dalam pelarut, sesuai prinsiplike dissolve like dimana suatu senyawa akanterlarut pada pelarut dengan sifat yang sama.Selain itu, perbedaan cara ekstraksi juga mempengaruhi senyawa yang akan terlarut pada sampel. Adapun pengujian yang dilakukan terhadap golongan senyawa-senyawa kimia yaitu sebagai berikut:

\section{Alkaloid}

Alkaloid mengandung atom nitrogen yang mempunyai pasangan elektron bebas sehingga dapat digunakan untuk membentuk ikatan kovalen koordinat dengan ion logam. Pada uji alkaloid dengan pereaksi Mayer, diperkirakan nitrogen pada. Alkaloid akan bereaksi dengan ion logam $\mathrm{K}+$ dari kalium tetraiodomerkurat(II) membentuk kompleks kalium-alkaloid yang mengendap (Marliana et al., 2005).Melalui penarikan alkaloid denganlarutan asam, alkaloid dapat diidentifikasi

langsung dengan satu atau lebih pereaksipengendap. Namun, alkaloid denganstruktur nitrogen heterosiklik, amin oksida, danalkaloid kuarterner tidak dapat terdeteksi dengan pereaksi pengendap hal ini akanmenghasilkan negatif pada pengujian (Fajarullah et al., 2014).

2. Flavonoid

Flavonoid dapat diuji keberadaannya dengan menggunakan reagen $\mathrm{Mg}$ dan $\mathrm{HCl}$ pekat, yang reaksi perubahannya akan membentuk warna kuning, merah atau jingga pada ekstrak yang mengandung flavonoid. Magnesium dan asam klorida pada uji Wilstater bereaksi membentuk gelembung-gelembung yang merupakan 
gas $\mathrm{H}_{2}$, sedangkan Logam $\mathrm{Mg}$ dan $\mathrm{HCl}$ pekat pada uji ini berfungsi untuk mereduksi inti benzopiron yang terdapat pada struktur flavonoid sehingga terbentuk perubahan warna menjadi merah atau jingga (Tiwariet al.,2011).

3. Saponin

Identifikasi adanya saponin menggunakan pereaksi berupa akuades menunjukkan pada ekstrak KJBEA dan KJKE70\% positif saponin dibuktikan dengan terbentuknya busa dan dapat bertahan tidak kurang dari 5 menit sedangkan ekstrak KJKEA dan KJBE70\% negatif saponin dikarenakan tidak adanya busa terbentuk. Timbulnya busa menunjukkan adanya glikosida yang mempunyai kemampuan membentuk buih dalam air yang terhidrolisis menjadi glukosa dan senyawa lainnya (Agustina et al., 2014).

4. Tanin

Identifikasi tanin dilakukan melalui penambahan $\mathrm{FeCl}_{3}$. Senyawa tanin adalah senyawa yang bersifat polar karena adanya gugus $\mathrm{OH}$, ketika ditambahkan $\mathrm{FeCl}_{3}$ $3 \%$ akan terjadi perubahan warna menjadi biru tua atau hijau kehitaman yang menandakan adanya tanin (Agoes, 2012).Terbentuknya warna hijau kehitaman pada ekstrak setelah ditambahkan $\mathrm{FeCl}_{3}$ dikarenakan tanin akan beraksi dengan ion $\mathrm{Fe}^{3+}$ membentuk senyawa kompleks (Harborne J.B, 1987).

5. Steroid dan triterpenoid

Reaksi positif uji triterpenoid dan steroid adalah dengan terbentuknya larutan berwarna merah untuk pertama kali pada reaksi positif triterpenoid dan selanjutnya terbentuk larutan berwarna biru dan hijau untuk reaksi positif steroid. Pada pengujian triterpenoid dan steroid analisis senyawa didasarkan pada kemampuan senyawa tersebut membentuk warna dengan $\mathrm{H}_{2} \mathrm{SO}_{4}$ pekat dalam pelarut asam asetat anhidrat, asam sulfat pekat dan kloroform (Wijayanti, 2016).

\section{KESIMPULAN}

Senyawa metabolit sekunder yang berhasil dideteksi pada ekstrak klika Kayu Jawa (Lannea coromendelica) adalah Flavonoid, saponin, tanin, dan steroid dan pelarut yang digunakan memiliki kemampuan mengekstraksi senyawa metabolit sekunder berbeda sesuai dengan tingkat kepolarannya.

\section{Ucapan Terima Kasih}

Ucapan terima kasih disampaikan kepada Seluruh dosen pengajar, staf pegawai dan laboran di JurusanBiologi Universitas Negeri Makassar atas segala ide, saran, serta dukungannya. 


\section{DAFTAR PUSTAKA}

Agoes, Azwar. 2012. Tanaman Obat Indonesia. Salemba Medika : Jakarta.

Agustina, Eva.2017. Uji Aktivitas Senyawa Antioksidan Dari Ekstrak Daun Tiin (Ficus Carica Linn) Dengan Pelarut Air, Metanol Dan Campuran Metanol-Air. KLOROFIL Vol. 1 No. 1, 2017: 38-47.ISSN 2598-6015.

Alviana, Nerissa., B. Boy R.S., Tri M.2016. Uji Efektivitas Antibakteri Ekstrak Etanol Daun Krisan (Chrysanthemum morifolium Syn. Dendrathema grandiflora) Terhadap Staphylococcus aureus dan Escherichia coli [Skripsi].Yogyakarta (ID): Universitas Atma Jaya Yogyakarta.

Anggitha, I. 2012. Performa Flokulasi Bioflokulan DYT pada Beragam Keasaman dan Kekuatan Ion terhadap Turbiditas Larutan Kaolin. Universitas Pendidikan Indonesia, Jakarta.

Fajarullah, Aulia., Henky I., Arief P.2014.Ekstraksi Senyawa Metabolit Sekunder Lamun Thalassodendron ciliatum Pada Pelarut Berbeda [skripsi]. Tanjung Pinang (ID): Universitas Maritim.

Harborne, J.B. 1987. Metode Fitokimia: Penuntun Cara Modern Menganalisis Tumbuhan. (Diterjemahkan Padmawinata, K., dan I. Sudiro). ITB:Bandung.

Manik, M.A., Wahid, S.M.A., Islam A. Pal., \& K.T. Ahmed. 2013. A Comparative Study of the Antioxidant, Antimicrobial and Thrombolytic Activity of the Bark and Leaves of Lannea coromandelica (Anacardiaceae). International Journal of Pharmaceutical Sciences and Research, Vol. 4(7), E-ISSN: 0975-8232, P-ISSN: 2320-5148.

Marliana, S. D., Suryanti, V., \& Suyono, 2005, Skrining Fitokimia dan Analisis Kromatografi Lapis Tipis Komponen Kimia Buah Labu Siam (Sechium edule Jacq. Swartz.) dalam Ekstrak Etanol, Jurnal biofarmasi 3 (1), 26-31.

Romadanu, Siti H.C., \& Shanti D.L. 2014. Pengujian Aktivitas Antioks Idan Ekstrak Bunga Lotus (Nelumbo Nucifera).Jurnal Antioksidan, Volume 2, Nomor 1.

Subhashini, P., Dilipan, E., Thangaradjou, T., dan Papenbrock, J. 2013. Bioactive Natural Products From Marine Angiosperm: Abundance and Functions. Natural Product Bioprospect: 129 - 136.

Tiwari, P., Kumar, B., Kaur, M., Kaur G., \& Kaur, H. 2011. Phytochemical Screening and Extraction: A Review. Internationale Pharmaceutica Sciencia,1(1).

Wijayanti, M.N. 2016. Uji Aktivitas Antioksidan dan Penetapan Kadar Fenolik Total Ekstrak Etanol Buah Buni (Antidesma bunius (L.) Spreng) dengan Metode 2,2diphenyl-1-picrylhydrazyl (DPPH) dan Metode Folin-Ciocalteu (Tesis). Yogyakarta (ID): Universitas Sanata Darma. 